\section{IJ§ER}

ISSN: 2149-5939
International Journal of Social Sciences and Education Research

Online, http://dergipark.gov.tr/ijsser

Volume: 4(4), 2018

\title{
Study of equation model for vertical jump test
}

\author{
Sercan Öncen ${ }^{1}$ Serkan Aydın ${ }^{2}$ Salih Pınar ${ }^{3}$
}

\begin{abstract}
Vertical jump is regarded as high-power output that can be reached by maximum muscular contraction taking place in less than one second and described as explosive power. Different results may be obtained in different methods applied to the same individual in vertical jump measurements.

In the study, it has been aimed to present an equation model at the end of determining the correlation between Stride Bluetooth Sensor (PSBS), Jumpster mobile phone jumping test program (JSP) and Vertical Jump Test (VJT) and deducing by simple linear regression model. 56 male and 34 female participants having 19,4 $\pm 1,1$ year, have been included in the study. Average height of jump of the participants have been measured as PSBS $32.8 \pm 8,2 \mathrm{~cm}$, $J S P 39.2 \pm 8.2 \mathrm{~cm}$ and VJT $43.6 \pm 8.6 \mathrm{~cm}$. There is a positive relationship of $r=792^{* *}, r=804^{* *}$ according to the Person correlation analysis results between the results of PSBS and JSP tests and VJT test.
\end{abstract}

Keywords: Jump terts, Equation model, Anaerobic power

\section{Introduction}

Jumping is carried out with contribution of knee extension and hip extension and plantar flexion of ankle (Hakkinen, 1991). How high the individual can jump depends upon the individual's phosphagen system biochemically and athlete's ability to use these phosphagen sources in high speed. This ability is assessed as the maximum height that can be reached after maximum contraction of contribution to the activity of fast contracting muscle fibers evaluated as explosive power (Beam WC \& Adams GM, 2011). The important factor affecting the ability of jumping can be described as the ability of all muscles joining the activity to work together successfully.

Assessing the jumping on different protocols, it has been observed that the same individual reaches different heights on different jumping protocols. In vertical jump tests, backward swinging and using the arms while jumping can improve the height of jump at the rate of $10 \%$ (Bosco \& Kobi, 1979). It has been thought that this improvement depends on neural harmony of the stretch reflex and the contribution of elastic energy source of muscle-tendon complex (Harman, 1990). Moreover, one of the important factors affecting the height of jump is the type of the stretching activities carried out during warm-up. Static stretching applications done after low density aerobic running affect the height of vertical jump negatively, dynamic warm-up applications affect positively (Gelen, 2008).

\footnotetext{
${ }^{1}$ Dr., Namık Kemal University, Physical Education and Sports, Turkey, soncen@nku.edu.tr

${ }^{2}$ Dr., Namık Kemal University, Physical Education and Sports, Turkey, saydin@nku.edu.tr

${ }^{3}$ Dr. Marmara University, Faculty of Sport Sciences, Turkey salih.pinar@marmara.edu.tr
} 
Öncen, S., Aydın, S., Pınar S. (2018). Study of equation model for vertical jump test. International Journal of

Social Sciences and Education Research, 4(4), 580-584.

Variations in body masses of the individuals will create differences over the power that must be applied during jump. In the calculations of the power created during jump, the individual's hang time (second), vertical change of position during jump (meter), body mass, (N) power components are taken into consideration. The measurement of these three variables enables the power to be calculated in terms of Watt (W) (Beam, WC \& Adams GM, 2011).

Two different aspects of power can be considered during vertical jump, average power derived from the force of gravity at the time of jump and peak power created at the acceleration phase of the jump, it is the calculation of the average workload within the unit of time covering the time at the descending phase besides the total time of impulse power. Absolute average power can be calculated as a numerical value in terms of Watt (Fox \& Mathews 1974). Absolute peak power of the individuals who completed vertical jump test on the power platform can be estimated from the height of jump (cm) and body mass (kg) (Sayers, 1999).

\section{Methodology}

When it is considered that warm-up has a positive effect on jump performance (De Vries, 1994), dynamic warm-up procedure for 5 or 10 minutes including vertical jumps has been applied for the participants (Sağiroğlu, 2017; Bosco, 1983).

Vertical Jump Test Procedure: The area of measurement has been determined as 1 meter wide and 4 meters length. They have $10 \mathrm{~cm}$ spaces located horizontally. Chalk has been applied on the fingertip of the dominant hand of the participant to jump in order to mark the height of jump.

Standing reach height, the highest point that the participant can reach without jumping on the measurement meter with the position that the dominant arm and leg comes next to the wall while participant sole is touching the ground and that participant marks using fingertips while his/her palm is touching the wall is determined. While taking the distance that the participants can reach while jumping, they are supposed to not moving their feet before jumping, moving their knees quickly downward, letting their arms swing and marking the highest point that the participant can reach. The participants are expected to carry out three suitable jumping trials at intervals of 2030 seconds (Sargent, 1921).

Methods of Jump Measurement: The product named Polar Stride Sensor Bluetooth Smart with the patent number US6584344 that was developed by Polar brand has been used. The sensor is a device located on the trainers and used for measuring the vertical jump height. Vertical jump measurement application named Jumpster which was developed by Skyhawk Media LLC has been used. The application works by a mobile phone. It has been immobilized to the waist region of each participant by a belt for the standardization of the measurements. The usage of the sensor and the mobile phone application has been practiced at the same time with the vertical jump test with regard to the standardization of the measurement. The best height of jump has been included in the statistical evaluation. Simple linear regression model has been applied in order to examine the linear relationship between Pearson correlation analysis and PSBS and JSP measurements and VJT dependent variable in determining the correlation of the two jump tests and vertical jump test.

In the evaluation of Lewis equation, the average power has been calculated by using the formula power $(W)=2.21 \times$ Body Mass $(N) x \sqrt{\text { vertical difference }}=2(m)$ (Fox, E.L. \& Mathews, 1974; Bosco, 1983). In the evaluation of Sayer equation, the peak power has been calculated by 
Öncen, S., Aydın, S., Pınar S. (2018). Study of equation model for vertical jump test. International Journal of Social Sciences and Education Research, 4(4), 580-584.

using the formula peak power $=[51.9 \times$ jump height $(\mathrm{cm})]+[48.9 \times$ Body Mass $(\mathrm{kg})]-2007$ (Sayers, 1999). The power has been calculated with relative environment as a result of dividing the absolute power values into the body weight $(\mathrm{W} / \mathrm{kg})$.

\section{Result}

Table 1. Age, height, weight and BMI statistics of participants

\begin{tabular}{lcccc}
\hline & $\mathrm{n}$ & Minimum & Maximum & The Mean \\
\hline Age / years & 90 & 18 & 26 & $19.4 \pm 1.12$ \\
Height / cm & 90 & 157 & 186 & $177 \pm 9,2$ \\
Weight / kg & 90 & 46 & 130 & $68.2 \pm 13.9$ \\
BMI & 90 & 21,36 & 24,28 & $22,34 \pm 1.9$ \\
\hline
\end{tabular}

56 male and 46 female participants have been included in the study. Average age of the participants is 19,4 years, average height is $177.92 \mathrm{~cm}$, average body weight is $68,2 \mathrm{~kg}$ and average BMI is 22,34 .

Table 2. Physical activity levels of participants

\begin{tabular}{lcccc}
\hline & $\mathrm{n}$ & $1-2$ days & $3-5$ days & Everyday \\
\hline $\begin{array}{l}30 \text { min and over } \\
\text { physical activity }\end{array}$ & 90 & $\% 28,9$ & $\% 45,6$ & $\% 25,6$ \\
\hline
\end{tabular}

In the evaluation of the participants according to their state of exercise for 30 minutes and over per week, the rate of the participants doing exercise for 30 minutes and over once or twice a week is $28,9 \%$, the rate of the participants doing exercise for 30 minutes and over 3 or 5 days a week is $45,6 \%$, the rate of the participants doing exercise for 30 minutes and over every day is $25,6 \%$.

Table 3. Jump heights of the participants $(\mathrm{cm})$

\begin{tabular}{lccccc}
\hline & $\mathrm{n}$ & Mean & SD & Min & Max \\
\hline VJT $(\mathrm{cm})$ & 90 & 43,6 & 8,66 & 21 & 68 \\
PSBS $(\mathrm{cm})$ & 90 & 32,8 & 8,20 & 18 & 53 \\
JSP $(\mathrm{cm})$ & 90 & 39,2 & 8,21 & 20 & 61 \\
\hline
\end{tabular}

Average jump heights of the participants one jump measured by three different methods have been measured as VJT 43,6 $\pm 8,66 \mathrm{~cm}$, PSBS $32,8 \pm 8.2 \mathrm{~cm}$ and JSP $39,2 \pm 8,21 \mathrm{~cm}$.

Table 4. Absolute average power according to Lewis equation

\begin{tabular}{lcccccc}
\hline & $\mathrm{n}$ & Mean & $(\mathrm{W} / \mathrm{kg})$ & SD & Min & Max \\
\hline VJT (W) & 90 & 978,1 & 14,34 & 25,23 & 541,68 & 1696,95 \\
PSBS & 90 & 847,9 & 12,43 & 23,61 & 463,06 & 1556,12 \\
(W) & 90 & 928,7 & 13,61 & 24,74 & 475,09 & 1677,56 \\
JSP (W) & 90 & & & \\
\hline
\end{tabular}


Öncen, S., Aydın, S., Pınar S. (2018). Study of equation model for vertical jump test. International Journal of

Social Sciences and Education Research, 4(4), 580-584.

Absolute average power according to Lewis equation has been calculated as VJT 978,1 \pm $25,23 \mathrm{~W}$, PSBS $847,9 \pm 23,61 \mathrm{~W}$ and JSP $928,7 \pm 24,74 \mathrm{~W}$. Relative average power values have been calculated as VJT 14,34 W, PSBS 12,43 W, JSP 13,61 W.

Table 5. Consumed peak power according to Sayer equation

\begin{tabular}{lcccccc}
\hline & $\mathrm{n}$ & Mean & $(\mathrm{W} / \mathrm{kg})$ & SD & Min & Max \\
\hline VJT (W) & 90 & 3591,39 & 52,65 & 98,12 & 1738,50 & 6046,80 \\
PSBS (W) & 90 & 3032,03 & 44,45 & 96,55 & 1375,20 & 5683,50 \\
JSP (W) & 90 & 3365,92 & 49,35 & 97,27 & 1427,10 & 5994,90 \\
\hline
\end{tabular}

Consumed peak power according to Sayer equation has been calculated as VJT 3591,39 \pm 98,12 W, PSBS 3032,03 \pm 96,55 W and JSP 3365,92 \pm 97,27 W. Relative peak power values have been calculated as VJT 52,65 W, PSBS 44,45 W, JSP 49,35 W.

Table 6. Pearson correlation analysis made in order to determine the relationship between the measurements obtained from PSBS and JSP tests and the VJT measurement

\begin{tabular}{lccc}
\hline & $\mathrm{n}$ & $\mathrm{r}$ & $\mathrm{p}$ \\
\hline PSBS & 90 & $792^{* *}$ &, 000 \\
JSP & 90 & $804^{* *}$ &, 000 \\
\hline
\end{tabular}

When the relationship between PSBS and JSP Tests and VJT has been examined, the correlation between PSBS measurement method and VJT $(\mathbf{r}=, 792)$ and JSP measurement method and VJT $(\mathbf{r}=, 804)$ has been found positive.

Table 7. Simple linear regression analysis between the measurements obtained from PSBS and JSP tests and the VJT measurement

\begin{tabular}{lcccccc}
\hline & $\mathrm{n}$ & $\mathrm{R}^{2}$ & Coefficients & $\mathrm{SD}$ & $\mathrm{t}$ & $\mathrm{p}$ \\
\hline \multirow{2}{*}{ PSBS } & 90 & 717 & 14,291 & 2,025 & 7,056 &, 000 \\
& & &, 893 & & & \\
JSP & 90 & 744 & 7,839 & 2,282 & 3,435 &, 001 \\
\hline
\end{tabular}

According to the results of Simple Linear Regression Analysis between the measurements obtained from PSBS and JSP Tests and the VJT measurement, it has been found as $\mathrm{R}^{2}$ PSBS $71,7 \%$ JSP $74,4 \%$.

\section{Discussion and conclusion}

Although there is no change with the height to be jumped, different jump measurements can be obtained through different measurement methods. In terms of science of training, it is very important for using time to get the measurements easily, practically and as quickly as possible on the field. For this reason, practical and problem solving features come into prominence as the first requested features. While jumping measurement method developed by Dudley Sargent in the first years of 1990s and which is a traditional jumping test is being determined by touching the highest point that can be reached, today these methods can be obtained by counting the time passed in the air after jumping (Sargent, 1921). The different methods (Beam, 2011, Sağiroğlu, 2017, Harman, 
Öncen, S., Aydın, S., Pınar S. (2018). Study of equation model for vertical jump test. International Journal of Social Sciences and Education Research, 4(4), 580-584.

1990) and warming protocols (Gelen, 2008) used in the measurement methods cause differences in the measured distance. Measurement methods such as PSBS and JSP can be seen as the two of the new daily methods which is practical and easy to use on the field. According to the statistical calculations of simple linear regression analysis, for the estimation of VJT test height that is one of the PSBS and JSP tests with the confidence interval of $95 \%, 71,7 \%, 74,4 \%\left(\mathrm{R}^{2}\right)$ of the change in the VJT test can be explained respectively by PSBS and JSP tests. For the remaining part of $28,3 \%$ for PSBS test and $25,6 \%$ for JBS test, other variables are needed. According to the regression estimation model, when PSBS test increases one unit, VJT height average increases 0,893 units. When JBS test increases one unit, VJT height average increases 0,911 units. According to the test statistics calculation, it has been calculated as VJT $=14,291+(0,893 \times$ PSBS $)$ and VJT= $7,839+(0,911 \times \mathrm{JSP})$. It means that the higher the correlation between two measurements is, the higher the relationship of these measurements with each other is. The correlation between PSBS $(\mathbf{r}=, 792)$ and JSP $(\mathbf{r}=, 804)$ tests and VJT is positive and high. High correlation between two applied measurement methods contains the level of applicability of the measurements with each other in a linear proportion. As a result of these study, the PSBS and JSP tests show that it can be suitable for the jumping test measurements.

\section{References}

Beam, W. C., \& Adams G. M. (2011) Exercise physiology-Laboratory manual (6th ed.).New York NY: McGraw Hill, 81

Bosco, C., \& Komi, P. V. (1979). Mechanical characteristics and fber composition of human leg extensor muscles. European Journal of Applied Pyhsiology, 41, 275-284

Bosco, C., Luhtanen, P., \& Komi P. V. (1983) $A$ simple method for measurement of mechanical power in jumping. European Journal of Applied Physiology, 50, 273-282

Bosco, C., Mognoni, P., \& Luhtanen, P.(1983) Relationship between isokinetic performansce and ballistic mevement. Eropean Journal of Applied Physiology, 51, 357-364

De Vries, H. A., \& Housh, T. J. (1994). Physiology of exercise for physical education, athletics and exercise science. Dubuque, IA, Brown \& Benchmark

Fox, E. L., \& Mathews, D. K. (1974). Interval training: conditioning for sports and general fitness. Philadelphia: W.B. Saunders College

Gelen, E. (2008) Farklı 1sınma protokollerinin sıçrama performansına, Spormetre Beden Eğitimi ve Spor Bilimleri Dergisi, 2008, 4, 207-212

Hakkinen, K. (1991). Force production characteristics of leg extensor, trunk flexor and extensor muscles inn male and female basketball players. Journal of Sports Medicine and Physical Fitness, 31, 325-331

Harman, E. A., Rosenstein, M. T., Frykman, P. N., \& Rosenstein, R. M. (1990). The effects of arm and countermovement on vertical jumping. Medicine and Science in Sports and Exercise, 22, 825-833

Sağiroğlu, İ,. Kurt, C., Pekünlü, E., \& Özsu, İ. (2017). Residual effects of static stretching and self-myofascial-release exercises on flexibility and lower body explosive strength in well-trained combat athletes, Isokinetics and Exercise Science, 25 (2), 135-141

Sargent, D.A. (1921). The physical test of a man. American Phsical Education Rewiew, 26, 188

Sayers, S. P., Harackiewicz, D. V., Harman, E. A., Frykman, P. N., Rosenstein,M.T. (1999). Crossvalidation of three jump power equation. Medicine and Science in Sports and Exercise, 31, 572-577

Sayers, S., Harackiewicz, D. V., Harman, E. A., Frykman, P. N., \& Rosenstein, M. T. (1999) Cross-validation of three jump power equations. Med Sci Sports Exerc. 31: 572. 